\title{
Colossal cages in zeolitic imidazolate frameworks as selective carbon dioxide reservoirs
}

\author{
Bo Wang ${ }^{1}$, Adrien P. Côté ${ }^{1}$, Hiroyasu Furukawa ${ }^{1}$, Michael O'Keeffe ${ }^{2}$ \& Omar M. Yaghi ${ }^{1}$
}

Zeolitic imidazolate frameworks (ZIFs) are porous crystalline materials with tetrahedral networks that resemble those of zeolites: transition metals $(\mathrm{Zn}, \mathrm{Co})$ replace tetrahedrally coordinated atoms (for example, $\mathrm{Si}$ ), and imidazolate links replace oxygen bridges $^{1}$. A striking feature of these materials is that the structure adopted by a given ZIF is determined by link-link interactions, rather than by the structure directing agents used in zeolite synthesis ${ }^{2}$. As a result, systematic variations of linker substituents have yielded many different ZIFs that exhibit known or predicted zeolite topologies. The materials are chemically and thermally stable, yet have the long-sought-after design flexibility offered by functionalized organic links and a high density of transition metal ions ${ }^{1-7}$. Here we report the synthesis and characterization of two porous ZIFs-ZIF-95 and ZIF-100 - with structures of a scale and complexity previously unknown in zeolites ${ }^{8-10}$. The materials have complex cages that contain up to 264 vertices, and are constructed from as many as 7,524 atoms. As expected from the adsorption selectivity recently documented for other members of this materials family ${ }^{3}$, both ZIFs selectively capture carbon dioxide from several different gas mixtures at room temperature, with ZIF-100 capable of storing 28 litres per litre of material at standard temperature and pressure. These characteristics, combined with their high thermal and chemical stability and ease of fabrication, make ZIFs promising candidate materials for strategies aimed at ameliorating increasing atmospheric carbon dioxide levels.

Since the initial observation ${ }^{4}$ that crystalline imidazolate frameworks with structures reminiscent of those exhibited by zeolites can be readily synthesized, a number of porous ZIFs have been developed ${ }^{1-3,5-7}$ by realizing that the $145^{\circ} \mathrm{Si}-\mathrm{O}$-Si bond angle in zeolites is close to the angle formed by imidazolates (IMs) when bridging transition metals (Fig. 1a). ZIFs reported so far-for example, those with RCSR (Reticular Chemistry Structure Resource) structure symbols sod, cag, mer, crb, dft, gis, rho, gme and lta-are predominantly simple uninodal (one type of tetrahedral centre) structures ${ }^{11}$. Whereas the structure of silicate-based zeolites is templated by structure directing agents (SDAs, typically organic amines) that remain as extra-framework entities, the structure adopted by a given ZIF predominantly depends on the type of IM and solvent used. Introduction of greater structural diversity to ZIF chemistry thus naturally begins with functionalization of IM linkers. In fact, it has been shown that link-link interactions can direct the formation of specific ZIF structures ${ }^{2}$. In the present case, an examination of 2-methylimidazolate (mIM) and benzimidazolate (bIM), which form ZIF-8 (structure symbol sod; Fig. 1b) and ZIF-11 (rho; Fig. 1c), respectively ${ }^{1}$, and modelling studies of sod and rho type structures, indicated that functionalization of the 6-membered ring (6MR) at the 4 or 5 position of bIM overcrowds links and inhibits the formation of rho (Fig. 1d) ${ }^{12}$. Thus we reasoned that proceeding with readily available 5-chlorobenzimidazolate (cbIM) should produce new ZIF topologies by increasing the IM girth (Fig. 1).

ZIF-95 was synthesized and structurally characterized by X-ray diffraction, and was found to be tetragonal (see Methods and Supplementary Information Section S1). It has a neutral framework with all $\mathrm{Zn}$ nodes tetrahedrally coordinated by cbIM. The 4-coordinated net of linked $\mathrm{Zn}$ atoms has a topology we name 'poz'. Salient features of the structure are two large cages (Fig. 2a-c): a $\left[3^{16} 4^{28} 8^{2} 12^{4}\right]$ poz $\mathrm{A}$ cage with $8 \mathrm{MR}$ and $12 \mathrm{MR}$ faces, and a $\left[3^{32} 4^{36} 8^{2} 10^{8} 12^{4}\right]$ poz $\mathrm{B}$ cage, with $8 \mathrm{MR}, 10 \mathrm{MR}$ and $12 \mathrm{MR}$ faces (in the symbols $\left[\ldots m^{n} \ldots\right]$ means that there are $n$ faces that are $m$-rings). There are also smaller $\left[4^{6} 10^{4}\right]$ poz $C$ cages and $\left[4^{6}\right]$ poz $D$ cages located at the interstices between $\mathrm{A}$ and $\mathrm{B}$ cages (Figs $2 \mathrm{a}-\mathrm{c}, 3 \mathrm{a}$ ).
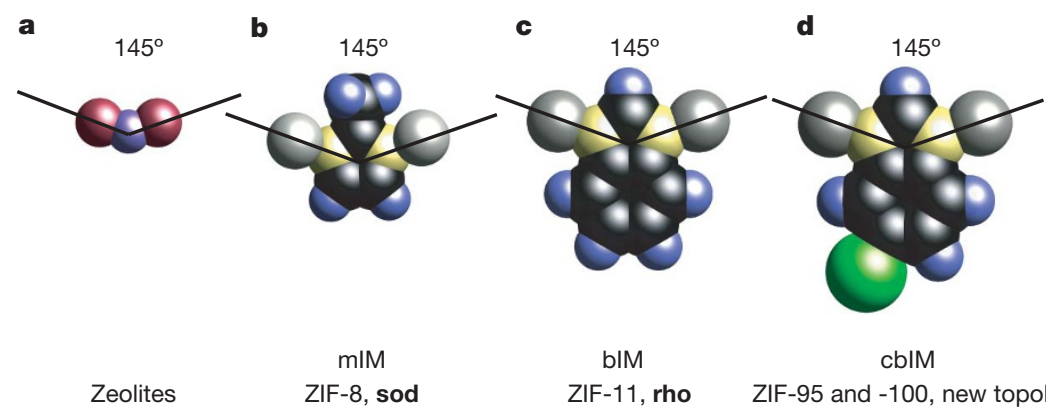

bIM ZIF-11, rho

$$
\text { ZIF-95 and }-100 \text {, new topology }
$$

(benzimidazolate), bIM, in ZIF-11 (rho). d, $\mathrm{Zn}_{2}$ (5-chlorobenzimidazolate), cbIM, in ZIF-95 and ZIF-100 (previously unknown topologies). 
a

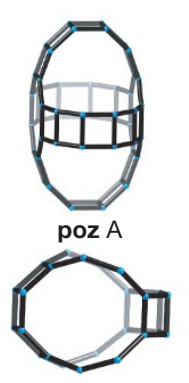

poz C

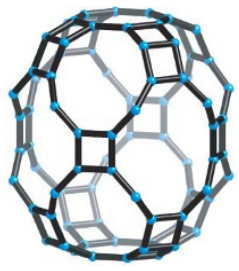

poz B

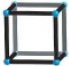

poz D b

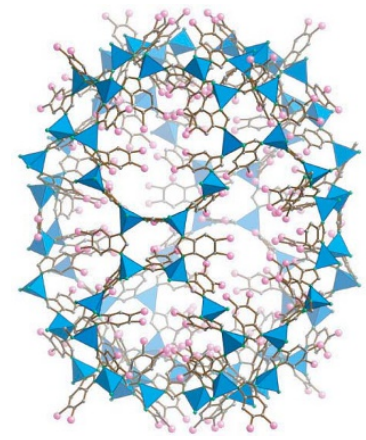

c
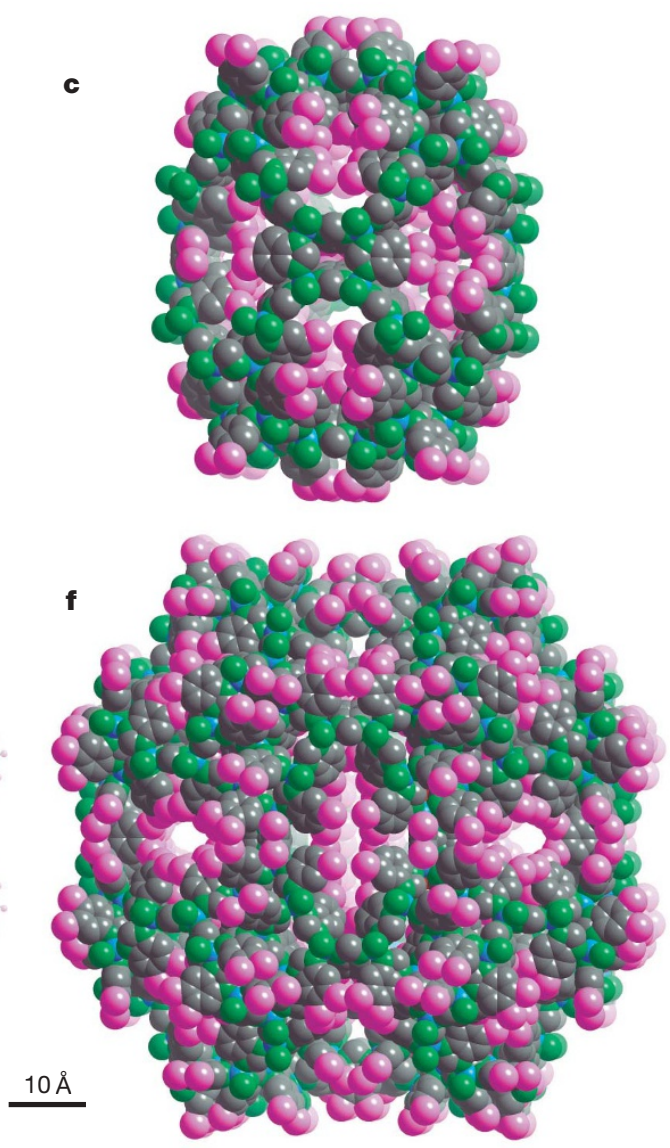

d

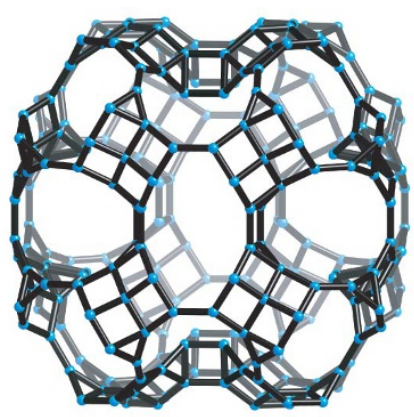

moz

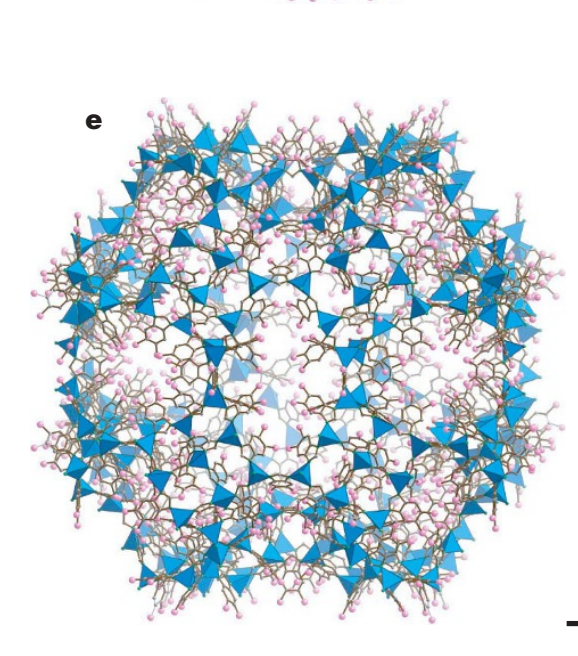

Figure 2 | The cages in ZIF-95 and ZIF-100. a, Ball and stick diagrams of the cages in ZIF-95; $\mathrm{Zn}$ in blue. b, Structure of poz B cage in ZIF-95; $\mathrm{ZnN}_{4}$ tetrahedra are shown in blue, $\mathrm{N}$ in green, $\mathrm{C}$ in grey and $\mathrm{Cl}$ in pink. c, Space filling diagram of poz $\mathrm{B}$ cage in $\mathrm{ZIF}-95$; $\mathrm{Zn}$ in blue, $\mathrm{N}$ in green, $\mathrm{C}$ in grey and

$\mathrm{Cl}$ in pink. d, Ball and stick diagram of moz cage in ZIF-100. e, Structure of moz cage in ZIF-100; $\mathrm{O}$ in red. $\mathbf{f}$, Space filling diagram of moz cage in ZIF100; $\mathrm{O}$ in red. All $\mathrm{H}$ atoms are omitted for clarity. Note that $\mathrm{Cl}$ atoms fill one half of the positions, however the disorder is illustrated here.
The packing of these cages can be seen from the illustration of them as a tiling in Fig. 3a. In Table 1 we list the numbers of faces, edges and vertices in these cages. It may be seen that the A cage has the same size, by this measure, as the faujasite 'super cage', which serves as a benchmark for large cage zeolites; the B cage is significantly larger. The pores of ZIF-95 are of ellipsoidal shape: from the van der Waals surfaces, the A cage measures $25.1 \times 14.3 \AA$ and comprises 1,056 atoms ( $48 \mathrm{Zn}, 504 \mathrm{C}, 288 \mathrm{H}, 144 \mathrm{~N}$ and $72 \mathrm{Cl}$ ). The B cage measures $30.1 \times 20.0 \AA$ A and comprises 1,648 atoms ( $80 \mathrm{Zn}, 784 \mathrm{C}, 448 \mathrm{H}, 224 \mathrm{~N}$ and $112 \mathrm{Cl}$ ) (Fig. 2b, c).

Restricting the water content of the reaction medium used for ZIF-95 synthesis promotes the crystallization of a new phase,

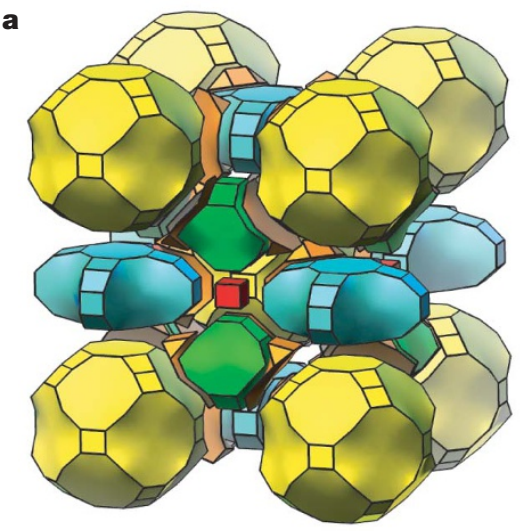

Figure 3 | The frameworks of ZIF-95 and ZIF-100 shown as natural tilings $^{27}$. a, Natural tiling of ZIF-95; the A and B cages are shown in blue and

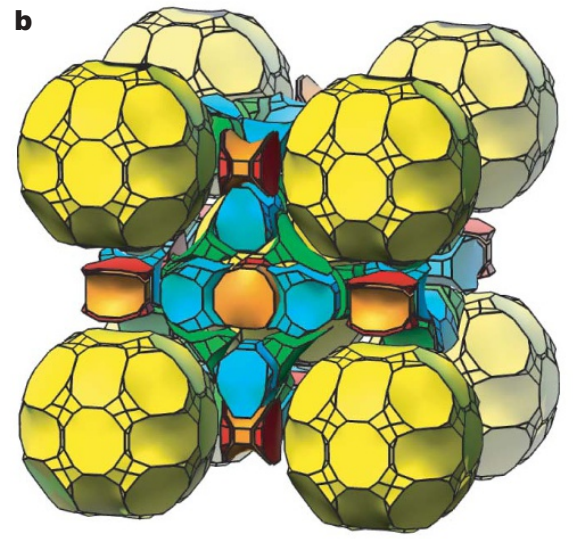

yellow, respectively. b, Natural tiling of ZIF-100; the giant cage is in yellow. 
Table 1 | Complexity of cages in FAU, MIL-101, mesoporous MOFs, and ZIFs

\begin{tabular}{|c|c|c|c|c|c|c|c|}
\hline \multirow[t]{2}{*}{$\overline{\text { Material }}$} & \multirow[t]{2}{*}{ Cages } & \multicolumn{2}{|c|}{ Cage size $(\AA)^{*}$} & \multirow[t]{2}{*}{ Vertices } & \multirow[t]{2}{*}{ Faces } & \multirow[t]{2}{*}{ Edges } & \multirow[t]{2}{*}{ Metal atoms per cage } \\
\hline & & Inner diameter & Outer diameter & & & & \\
\hline$\overline{\text { FAU }}$ & Super cage & 14.1 & 18.1 & 48 & 26 & 72 & 48 \\
\hline ZIF-95 & poz A & $25.1 \times 14.3$ & $33.6 \times 23.9$ & 48 & 26 & 72 & 48 \\
\hline ZIF-95 & poz B & $30.1 \times 20.0$ & $41.1 \times 33.9$ & 80 & 34 & 112 & 80 \\
\hline MIL-101 13 & Large cage & 33.8 & 46.7 & 28 & 16 & 42 & 126 \\
\hline Mes. MOF-1 $1^{14}$ & L cage & 47.1 & 59.5 & 28 & 16 & 42 & 84 \\
\hline ZIF-100 & $\mathrm{moz}$ & 35.6 & 67.2 & 264 & 182 & 444 & 264 \\
\hline
\end{tabular}

Mes., mesoporous. FAU, faujasite.

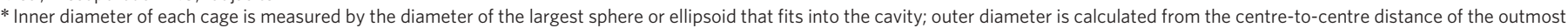
atoms of each cage.

ZIF-100. Less hydrated conditions are achieved by using anhydrous $\mathrm{Zn}\left(\mathrm{O}_{3} \mathrm{SCF}_{3}\right)_{2}$ in place of $\mathrm{Zn}\left(\mathrm{NO}_{3}\right) \cdot 4 \mathrm{H}_{2} \mathrm{O}$. Control experiments rule out anions as SDAs (see Methods). Full understanding of the crystallization processes for ZIF-100 and ZIF-95 is difficult to attain, but the fact that cbIM leads to new ZIF structures, and not rho, supports our thesis that strategic link functionalization can access unrealized structural diversity. ZIF-100 was found to have the composition $\mathrm{Zn}_{20}(\mathrm{cbIM})_{39}(\mathrm{OH})$, where one $\mathrm{Zn}$ atom (labelled $\mathrm{Zn} 8$, see Supplementary Information Section S1) is only tri-coordinated by cbIM.

$\mathrm{X}$-ray diffraction techniques were used to determine the structure of ZIF-100. Initial X-ray photographs of the crystals clearly revealed a dense diffraction pattern indicative of a very large unit cell. ZIF-100 has $\operatorname{Im} \overline{3}$ symmetry, with a unit cell parameter $a=71.9797(4) \AA$ and unit cell volume of $372,932(4) \AA^{3}$. Its primitive cell volume of $1.86 \times 10^{5} \AA^{3}$ makes ZIF-100 one of the largest inorganic structures ever determined: it exceeds the primitive cell volume $\left(1.75 \times 10^{5} \AA^{3}\right)$ of the previous record holder, a metal-organic framework (MOF) designated MIL-101 (ref. 13), although a structurally related and more recently reported MOF has an even larger cell ${ }^{14}$.

Application of conventional small molecule chemical crystallographic methods was inadequate in achieving a structural solution for ZIF-100. Thus a new strategy was developed, which borrows from techniques and computational methods used for biological macromolecule crystallography (see Supplementary Information Section S1). Here, dual-space direct-methods procedures (Shakeand-Bake v2.0) produced initial phases from the observed structure factors $\left(F_{\mathrm{obs}}\right)$ and electron density maps identifying the positions of heavy atoms $(\mathrm{Zn} \text { and disordered } \mathrm{Cl})^{15}$. Positions of $\mathrm{C}, \mathrm{H}$ and $\mathrm{N}$ were not revealed at this stage. From our previous ZIF studies ${ }^{1}$ we knew that the nearest neighbour $\mathrm{Zn}-\mathrm{Zn}$ distances measure 6.0(4) $\AA$, which is close to the $\mathrm{Zn}-\mathrm{Cl}$ distance of 6.0-6.5 $\AA$ expected from molecular modelling. This created a challenge for initial placement of cbIM C and $\mathrm{N}$ atoms, which was reconciled through systematic positioning of a rigid five-membered $\mathrm{C}_{3} \mathrm{~N}_{2}$ IM ring and testing for all possible connections between heavy atom positions. Upon refinement, correct IM placement was identified by: (1) obtaining chemically logical bond lengths and angles, and (2) the emergence of peaks from subsequent Fourier difference maps corresponding to atoms from $6 \mathrm{MRs}$ of cbIM which are geometrically aligned to the positions of disordered $\mathrm{Cl}$ atoms. Given the magnitude of the ZIF-95 and ZIF-100 structures, their high porosity, and the population of their pores with highly disordered guest molecules, the final refined structures have expectedly elevated reliability factors compared to those from small molecule crystallography. However, bond lengths and angles in the final structures are statistically and chemically reasonable values. Indeed, the reliability factors are better than those generally obtained for biological crystal structures, indicating that our structural refinements accurately describe the composition and atomic connectivity of ZIF-95 and ZIF-100.

ZIF-100 has a beautifully complex structure constructed from simple building blocks (Figs $2 \mathrm{~d}-\mathrm{f}$ and $3 \mathrm{~b}$ ). Of the ten $\mathrm{Zn}$ atoms that form the $(3,4)$-coordinated net with the topology symbolized as $\mathbf{m o z}$, nine are connected to four cbIM linkers and the remaining one ( $\mathrm{Zn} 8)$ is connected to three linkers. The salient feature is a giant cage $\left[3^{48} 4^{108} 12^{26}\right]$ with 264 vertices (see Figs $2 \mathrm{~d}-\mathrm{f}$ and $3 \mathrm{~b}$, and Table 1 ), which is one of the most complex polyhedra ever found in an inorganic material. This $\mathbf{m o z}$ cage $(95.6 \mathrm{kDa})$ is built from 7,524 atoms$264 \mathrm{Zn}, 3,604 \mathrm{C}, 2,085 \mathrm{H}, 26 \mathrm{O}, 1,030 \mathrm{~N}, 515 \mathrm{Cl}$-and has a $67.2 \AA$ outer sphere diameter and a $35.6 \AA$ inner sphere diameter. The inner sphere diameter is determined by fitting a sphere from the centroid of the cage to the van der Waals surface of its wall. In comparison, the corresponding distances in the faujasite super cage are $18.1 \AA$ and 14.1 $\mathrm{\AA}$ (Table 1).

The remarkably large pore sizes prompted us to examine the structural and thermal stability of these ZIFs and their gas uptake behaviour. Thermal gravimetric analysis and powder X-ray diffraction studies revealed a thermal stability range up to $500{ }^{\circ} \mathrm{C}$ for both ZIF-95 and ZIF-100 (Supplementary Information Sections S2 and S4). Full activation of ZIF-95 and ZIF-100 was achieved by soaking crystals in acetone or methanol, respectively, for $72 \mathrm{~h}$ and heating at $50{ }^{\circ} \mathrm{C}$ for $10 \mathrm{~h}$ under reduced pressure $\left(10^{-3}\right.$ torr $)$ and then at $100{ }^{\circ} \mathrm{C}$ for $12 \mathrm{~h}$; their permanent porosity subsequently was proven using a $\mathrm{N}_{2}$ or $\mathrm{Ar}$ adsorption measurement (Supplementary Information Section S5). The Langmuir surface areas were $1,240 \mathrm{~m}^{2} \mathrm{~g}^{-1}$ and $780 \mathrm{~m}^{2} \mathrm{~g}^{-1}$ for ZIF-95 and ZIF-100, respectively (Fig. 4a, b), which is more than double those of the most porous zeolites. The BET method ${ }^{16}$ yielded surface areas of $1,050 \mathrm{~m}^{2} \mathrm{~g}^{-1}$ and $595 \mathrm{~m}^{2} \mathrm{~g}^{-1}$, respectively.

Slow diffusion of gas was evident for both ZIFs during adsorption analysis. The slow diffusion can be ascribed to pore apertures that are not much larger than the kinetic diameter of many small gases and therefore restrict migration of the gases into the pores. The two ZIFs thus uniquely combine huge cavities $(24.0 \AA$ and $35.6 \AA$ for ZIF-95 and ZIF-100, respectively) and highly constricted windows (largest apertures, $3.65 \AA$ and $3.35 \AA$, respectively), which points to their possible utility in carbon dioxide capture and storage. It is now commonly believed that carbon dioxide emissions from burning of fossil fuels in power plants and automobiles are altering the temperature of the atmosphere and the acidity of the oceans with undesirable consequences for the Earth's environment ${ }^{17}$. It has been shown ${ }^{3,18-22}$ that MOFs and ZIFs can hold large amounts of gases, including carbon dioxide, and that gas uptake can be selective. But it remains challenging to efficiently and selectively capture $\mathrm{CO}_{2}$ from industrial emission streams (which invariably contain other gases such as $\mathrm{CH}_{4}, \mathrm{~N}_{2}$ and so on); such a capability could allow for an efficient and economic reduction in $\mathrm{CO}_{2}$ emissions ${ }^{23,24}$.

Carbon dioxide, methane, carbon monoxide and nitrogen adsorption isotherms were measured for both ZIFs (Fig. 4b), which clearly show a disproportionately high affinity and capacity for $\mathrm{CO}_{2}$ (Fig. 4b). ZIF-100 is seen to outperform ZIF-95 and the prototypical adsorbent BPL carbon, which is widely used in industry owing to its ease of desorption and regeneration ${ }^{25}$. We note that some zeolite materials outperform not only BPL carbon but also our ZIFs in terms of selective $\mathrm{CO}_{2}$ adsorption ${ }^{26}$, but regeneration difficulties mean that their suitability for practical use is uncertain ${ }^{25}$ and they were therefore not included in the comparative adsorption measurements. Figure $4 \mathrm{~b}$ also illustrates that both ZIFs show complete reversibility 

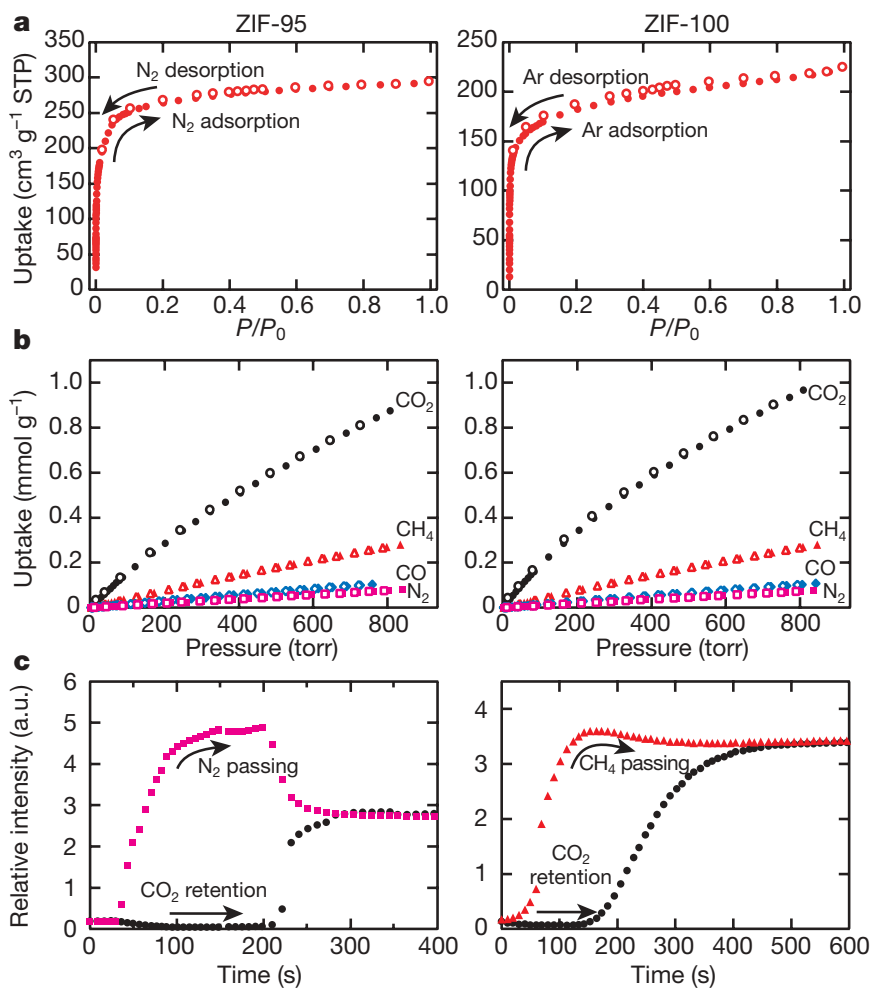

Figure 4 | Gas adsorption isotherms of ZIF-95 (left) and ZIF-100 (right). a, b, $\mathrm{N}_{2}$ at $77 \mathrm{~K}$ for ZIF-95 (a, left); Ar at $87 \mathrm{~K}$ for ZIF-100 (a, right); $\mathrm{CO}_{2}$ (black, circles), $\mathrm{CH}_{4}$ (red, triangles), $\mathrm{CO}$ (blue, diamonds) and $\mathrm{N}_{2}$ (pink, rectangles) at $298 \mathrm{~K}$ for ZIF-95 (b, left) and ZIF-100 (b, right); the filled and open shapes represent adsorption and desorption, respectively. $P / P_{0}$, relative pressure at the saturation vapour pressure of the adsorbate gas. c, Breakthrough curves, $\mathrm{N}_{2}$ (pink, rectangles) and $\mathrm{CO}_{2}$ (black, circles) for ZIF-95 using a $\mathrm{CO}_{2} / \mathrm{N}_{2}$ gas mixture (left); $\mathrm{CH}_{4}$ (red, triangles) and $\mathrm{CO}_{2}$ (black, circles) for ZIF-100 using a $\mathrm{CO}_{2} / \mathrm{CH}_{4}$ gas mixture (right). The relative intensities of each gas passing through the ZIF-95- and ZIF-100-packed column were obtained using a mass spectrometer to detect ion peaks at $m / z^{+}=44\left(\mathrm{CO}_{2}\right), 16\left(\mathrm{CH}_{4}\right), 28\left(\mathrm{~N}_{2}\right)$ and $12(\mathrm{CO})$. Mean value from multiple parallel experiments $(n \geq 3$, standard deviation $\sigma \leq 5 \%$ for all isotherms and $\leq 6 \%$ for breakthrough curves) was adopted for each data point. Owing to the slow diffusion, ZIF-100 does not exhibit a stepped isotherm as expected for a mesoporous material.

of adsorption, indicating that they might serve as selective carbon dioxide reservoirs before the gas is processed further (for example, injected into an underground geologic formation). More detailed analysis of the data in Fig. $4 \mathrm{~b}$ indicates that one litre of ZIF-100 can hold up to 28.21 (55.4 g, or $1.7 \mathrm{mmol}$ per g of ZIF-100) of $\mathrm{CO}_{2}$ at $273 \mathrm{~K}$ and $15.9 \mathrm{l}(31.2 \mathrm{~g})$ at $298 \mathrm{~K}$, with a single $\mathbf{m o z}$ cage capturing as many as $121 \mathrm{CO}_{2}$ molecules at $273 \mathrm{~K}$ and 68 molecules at $298 \mathrm{~K}$ and ambient pressure. These adsorption characteristics are in line with the recent report ${ }^{3}$ of 11 of ZIF-69 storing 82.61 of $\mathrm{CO}_{2}$ at $273 \mathrm{~K}$. The selectivity of ZIFs for carbon dioxide thus clearly exceeds that of BPL carbon (Table 2 and Supplementary Information Section S5; see also ref. 3). Some $\mathrm{MOFs}^{20}$ have a higher overall capacity for carbon dioxide, but they do not show the level of selectivity observed with ZIFs.

Preliminary breakthrough experiments (see Methods and Supplementary Information Section S6) were also carried out to show that carbon dioxide can be held in the pores of ZIF-95 and ZIF-100 when exposed to streams containing binary mixtures of $\mathrm{CO}_{2} / \mathrm{CH}_{4}, \mathrm{CO}_{2} / \mathrm{CO}$ or $\mathrm{CO}_{2} / \mathrm{N}_{2}(50: 50 \mathrm{v} / \mathrm{v})$. Figure $4 \mathrm{c}$ shows the results for $\mathrm{CO}_{2} / \mathrm{N}_{2}$ passing through $1.2 \mathrm{~g}$ of ZIF-95 and $\mathrm{CO}_{2} / \mathrm{CH}_{4}$ passing through $1.1 \mathrm{~g}$ of ZIF-100. It is very clear that in both cases only carbon dioxide is retained in the pores while the other gas passes through without hindrance; this observation lends further support to
Table 2 | Gas separation selectivity of ZIFs and BPL carbon

\begin{tabular}{lcccc}
\hline Material & Gas pairs & ZIF selectivity*28 & $\begin{array}{c}\text { BPL carbon } \\
\text { selectivity }\end{array}$ & $\begin{array}{c}\text { Ratio } \\
\text { ZIF/BPL carbon* }\end{array}$ \\
\hline ZIF-100 & $\mathrm{CO}_{2} / \mathrm{CH}_{4}$ & $5.9 \pm 0.4$ & 2.5 & $2.4 \pm 0.2$ \\
ZIF-100 & $\mathrm{CO}_{2} / \mathrm{CO}^{25}$ & $17.3 \pm 1.5$ & 7.5 & $2.3 \pm 0.2$ \\
ZIF-100 & $\mathrm{CO}_{2} / \mathrm{N}_{2}$ & $25.0 \pm 2.4$ & 11.1 & $2.3 \pm 0.2$ \\
ZIF-95 & $\mathrm{CO}_{2} / \mathrm{CH}_{4}$ & $4.3 \pm 0.4$ & 2.5 & $1.7 \pm 0.2$ \\
ZIF-95 & $\mathrm{CO}_{2} / \mathrm{CO}_{2}$ & $11.4 \pm 1.1$ & 7.5 & $1.5 \pm 0.1$ \\
ZIF-95 & $\mathrm{CO}_{2} / \mathrm{N}_{2}$ & $18.0 \pm 1.7$ & 11.1 & $1.6 \pm 0.2$ \\
\hline
\end{tabular}

* See Supplementary Information Section S5.

the idea of using ZIFs as selective carbon dioxide reservoirs. We attribute the high selectivity for carbon dioxide seen here to the combined effects of the slit width of the pore apertures being similar in size to carbon dioxide (kinetic diameter $\sim 3 \AA$ ), and the strong quadrupolar interactions of carbon with nitrogen atoms present in the links.

\section{METHODS SUMMARY}

Synthesis of compounds. Light yellow crystalline plates of ZIF-95 (framework composition: $\mathrm{Zn}(\mathrm{cbIM})_{2}$ ) were isolated from the reaction of a mixture containing $\mathrm{Zn}\left(\mathrm{NO}_{3}\right)_{2} \cdot 4 \mathrm{H}_{2} \mathrm{O}$, 5-chlorobenzimidazole (cbIM), $N$, N-dimethylformamide (DMF) and water at $120^{\circ} \mathrm{C}(75.0 \%$ yield based on zinc). Precise control of water added and use of $\mathrm{Zn}\left(\mathrm{O}_{3} \mathrm{SCF}_{3}\right)_{2}$ under the same conditions yields dark yellow cubic crystals of ZIF-100 (framework composition: $\left.\mathrm{Zn}_{20}(\mathrm{cbIM})_{39}(\mathrm{OH})\right)(70.5 \%$ yield). These crystals were used for single-crystal X-ray diffraction studies. Both compounds were prepared as microcrystalline powder on the gram scale for examination of their porosity and selectivity to gases.

X-ray single-crystal diffraction studies. ZIF-95 is tetragonal: $I 4 / \mathrm{mmm}$, $a=b=38.7657(4) \AA, c=56.454(1) \AA ; \quad V=84,837(2) \AA^{3}$. Total reflections, 77,043; independent reflections, 3,666 $(\mathrm{R}(\mathrm{int})=0.1660)$; parameters, 296; $\mathrm{R} 1=0.1699, \quad \mathrm{wR} 2=0.2750$. ZIF-100 is cubic: $\operatorname{Im} \overline{3}, \quad a=71.9797(4) \AA$, $V=372,932(4) \AA^{3}$. Total reflections, 783,540; independent reflections, 25,973 $(\mathrm{R}($ int $)=0.2642$ ); parameters, $786 ; \mathrm{R} 1=0.1798$, wR2 $=0.4315$ (Supplementary Information Section S1).

Gas adsorption and separation measurements. The $\mathrm{N}_{2}$ (for ZIF-95, $77 \mathrm{~K}$ ) and $\mathrm{Ar}$ (for ZIF-100, 87 K) isotherms were measured for ZIF-95 and ZIF-100. ZIF-95 (ZIF-100): an apparent surface area of $1,240(780) \mathrm{m}^{2} \mathrm{~g}^{-1}$ and a micropore volume of $0.43(0.37) \mathrm{cm}^{3} \mathrm{~g}^{-1}$ were found (Supplementary Information Section S5). The gas-separation properties of ZIF-95 and ZIF-100 were derived from gas adsorption isotherms and by breakthrough experiments using $\mathrm{CO}_{2} / \mathrm{CH}_{4}, \mathrm{CO}_{2} / \mathrm{N}_{2}$ or $\mathrm{CO}_{2} / \mathrm{CO}$.

Full Methods and any associated references are available in the online version of the paper at www.nature.com/nature.

\section{Received 11 October 2007; accepted 29 February 2008.}

1. Park, K.-S. et al. Exceptional chemical and thermal stability of zeolitic imidazolate frameworks. Proc. Natl Acad. Sci. USA 103, 10186-10191 (2006).

2. Hayashi, H., Côté, A. P., Furukawa, H., O'Keeffe, M. \& Yaghi, O. M. Zeolite A imidazolate frameworks. Nature Mater. 6, 501-506 (2007).

3. Banerjee, R. et al. High-throughput synthesis of zeolitic imidazolate frameworks and application to $\mathrm{CO}_{2}$ capture. Science 319, 939-943 (2008).

4. Tian, Y.-Q. et al. Two polymorphs of cobalt(II) imidazolate polymers synthesized solvothermally by using one organic template $N, N$-dimethylacetamide. Inorg. Chem. 43, 4631-4635 (2004).

5. Tian, Y.-Q. et al. Design and generation of extended zeolitic metal-organic frameworks (ZMOFs): Synthesis and crystal structures of zinc(II) imidazolate polymers with zeolitic topologies. Chem. Eur. J. 13, 4146-4154 (2007).

6. Huang, X.-C., Lin, Y.-Y., Zhang, J.-P. \& Chen, X.-M. Ligand-directed strategy for zeolite-type metal-organic frameworks: Zinc(II) imidazolates with unusual zeolitic topologies. Angew. Chem. Int. Edn 45, 1557-1559 (2006).

7. Liu, Y., Kravtsov, V. Ch., Larsena, R. \& Eddaoudi, M. Molecular building blocks approach to the assembly of zeolite-like metal-organic frameworks (ZMOFs) with extra-large cavities. Chem. Commun. 14, 1488-1490 (2006)

8. Baerlocher, C. \& McCusker, L. B. Database of Zeolite Structures 〈http://www.izastructure.org/databases/ $>$ (accessed, 11 October 2007).

9. Davis, M. E. Ordered porous materials for emerging applications. Nature 417, 813-821 (2002).

10. Thomas, J. M. Design, synthesis and in situ characterization of new solid catalysts Angew. Chem. Int. Edn 38, 3588-3628 (1999).

11. Ockwig, N. W., Delgado-Friedrichs, O., O'Keeffe, M. \& Yaghi, O. M. Reticular chemistry: Occurrence and taxonomy of nets and grammar for the design of frameworks. Acc. Chem. Res. 38, 176-182 (2005). 
12. Cerius2. Modeling Environment (Molecular Simulations, San Diego, California, 1999).

13. Férey, G. et al. A chromium terephthalate-based solid with unusually large pore volumes and surface area. Science 309, 2040-2042 (2005).

14. Park, Y. K. et al. Crystal structure and guest uptake of a mesoporous metal-organic framework containing cages of 3.9 and $4.7 \mathrm{~nm}$ in diameter. Angew. Chem. Int. Edn 46, 8230-8233 (2007)

15. Weeks, C. M. \& Miller, R. The design and implementation of SnB version 2.0. J. Appl. Crystallogr. 32, 120-124 (1999).

16. Walton, K. S. \& Snurr, R. Q. Applicability of the BET method for determining surface areas of microporous metal-organic frameworks. J. Am. Chem. Soc. 129, 8552-8556 (2007).

17. Houghton, J. T., Meira Filho, L. G., Griggs, D. J. \& Noguer, M. Implications of Proposed $\mathrm{CO}_{2}$ Emissions Limitations (Technical Paper IV, IPCC, Geneva, Switzerland, 1997).

18. Li, H., Eddaoudi, M., Groy, T. L. \& Yaghi, O. M. Establishing microporosity in open metal-organic frameworks: Gas sorption isotherms for $\mathrm{Zn}(\mathrm{BDC})(\mathrm{BDC}=1,4$ benzenedicarboxylate). J. Am. Chem. Soc. 120, 8571-8572 (1998).

19. Millward, A. R. \& Yaghi, O. M. Metal-organic frameworks with exceptionally high capacity for storage of carbon dioxide at room temperature. J. Am. Chem. Soc. 127, 17998-17999 (2005).

20. Surblé, S. et al. Synthesis of MIL-102, a chromium carboxylate metal-organic framework, with gas sorption analysis. J. Am. Chem. Soc. 128, 14889-14896 (2006).

21. Maji, T. K., Mostafa, G., Changa, H.-C. \& Kitagawa, S. Porous lanthanide-organic framework with zeolite-like topology. Chem. Commun. 19, 2436-2438 (2005).

22. Horike, S., Tanaka, D., Nakagawa, K. \& Kitagawa, S. Selective guest sorption in an interdigitated porous framework with hydrophobic pore surfaces. Chem. Commun. 32, 3395-3397 (2007).
23. Sircar, S. Basic research needs for design of adsorptive gas separation processes. Ind. Eng. Chem. Res. 45, 5435-5448 (2006).

24. Sasaki, A., Matsumoto, S., Fujitsuka, M., Shinoki, T.\& Tanaka, T. CO 2 recovery in molten carbonate fuel cell system by pressure swing adsorption. IEEE Trans. Energy Convers. 8, 26-32 (1993).

25. Sircar, S., Golden, T. C. \& Rao, M. B. Activated carbon for gas separation and storage. Carbon 34, 1-12 (1996).

26. Sircar, S. \& Golden, T. C. Isothermal and isobaric desorption of carbon dioxide by purge. Ind. Eng. Chem. Res. 34, 2881-2888 (1995).

27. Blatov, V. A., Delgado-Friedrichs, O., O'Keeffe, M. \& Proserpio, D. M. Threeperiodic nets and tilings: natural tilings for nets. Acta Crystallogr. A 63, 418-423 (2007).

28. Malek, A. \& Farooq, S. Comparison of isotherm models for hydrocarbon adsorption on activated carbon. Am. Inst. Chem. Eng. J. 42, 3191-3201 (1996).

Supplementary Information is linked to the online version of the paper at wwW.nature.com/nature.

Acknowledgements Funding was provided by BASF Ludwigshafen-Germany (synthesis), US Department of Defense (DTRA, separation instruments) and US Department of Energy (BES-Separation Program, gas separations). We acknowledge J. Eckert, D. Tranchemontagne and D. Britt (Yaghi group) for discussions.

Author Information Reprints and permissions information is available at www.nature.com/reprints. Crystallographic data for the reported crystal structures have been deposited at the Cambridge Crystallographic Data Centre via www.ccdc.cam.ac.uk with codes 668214 (ZIF-95) and 668215 (ZIF-100). Correspondence and requests for materials should be addressed to O.M.Y. (yaghi@chem.ucla.edu). 


\section{METHODS}

General. 5-chlorobenzimidazole (cbIM), zinc(II) trifluoromethanesulphonate, $\mathrm{Zn}\left(\mathrm{O}_{3} \mathrm{SCF}_{3}\right)_{2}$, anhydrous $\mathrm{N}, \mathrm{N}$-dimethylformamide (DMF), acetone and methanol were purchased from Aldrich Chemical Co.; imidazole and DMF were purchased from Fisher Scientific International, Inc. Zinc(II) nitrate tetrahydrate, $\mathrm{Zn}\left(\mathrm{NO}_{3}\right)_{2} \cdot 4 \mathrm{H}_{2} \mathrm{O}$, was purchased from EM Science. All starting materials were used without further purifications. Weighing and transferring zinc(II) trifluoromethanesulphonate was performed in a glove box. All the other experimental operations, unless otherwise noted, were performed in air. Single-crystal X-ray diffraction data were collected using a Bruker SMART APEX-II three-circle diffractometer equipped with a CCD (charge-coupled device) area detector operated at $1,200 \mathrm{~W}(40 \mathrm{kV}, 30 \mathrm{~mA})$ to generate $\mathrm{Cu} \mathrm{K} \alpha$ radiation $(\lambda=1.5417 \AA$ ) (Supplementary Information Section S1). Powder X-ray diffraction data were collected using a Bruker D8 Discover $\theta-2 \theta$ diffractometer in reflectance Bragg-Brentano geometry at $40 \mathrm{kV}, 40 \mathrm{~mA}(1,600 \mathrm{~W})$ for $\mathrm{Cu} \mathrm{K} \alpha_{1}$ radiation $(\lambda=1.5406 \AA$ ) (Supplementary Information Section S2). Fouriertransform infrared spectra (FT-IR) of samples prepared as KBr pellets were measured using a Nicolet FT-IR Impact 400 system (Supplementary Information Section S3). Thermal gravimetric analysis was carried out using a TA Q500 thermal analysis system (Supplementary Information Section S4).

Synthesis of ZIF-95. A solid mixture of zinc(II) nitrate tetrahydrate $\left(\mathrm{Zn}\left(\mathrm{NO}_{3}\right)_{2} \cdot 4 \mathrm{H}_{2} \mathrm{O}, \quad 1.044 \mathrm{~g}, \quad 4.0 \mathrm{mmol}\right)$ and cbIM $\left(\mathrm{C}_{7} \mathrm{H}_{5} \mathrm{~N}_{2} \mathrm{Cl}, 6.106 \mathrm{~g}\right.$, $40.0 \mathrm{mmol}$ ) was dissolved in $295 \mathrm{ml} \mathrm{DMF}$ and $5 \mathrm{ml} \mathrm{H}_{2} \mathrm{O}$ in a $500 \mathrm{ml}$ container. The container was capped and heated at $120^{\circ} \mathrm{C}$ for $72 \mathrm{~h}$ to give light yellow plate crystals. The reaction mixture was allowed to cool gradually to room temperature and crystals were washed with DMF and dried in air (yield: $1.103 \mathrm{~g}, 75 \%$ based on $\left.\mathrm{Zn}\left(\mathrm{NO}_{3}\right)_{2} \cdot 4 \mathrm{H}_{2} \mathrm{O}\right)$. Elemental microanalysis for $\mathrm{Zn}(\mathrm{cbIM})_{2} \equiv$ $\mathrm{C}_{14} \mathrm{H}_{8} \mathrm{~N}_{4} \mathrm{Cl}_{2} \mathrm{Zn}_{1}$, calculated based on framework only (\%): C, 45.63; H, 2.19; N, 15.20; Cl, 19.24; Zn, 17.74. Found (\%): C, 46.06; H, 2.40; N, 14.38; Cl, 19.13; $\mathrm{Zn}, 18.17$. FT-IR $\left(\mathrm{KBr}, 4,000-400 \mathrm{~cm}^{-1}\right)$ : 3,426(br), 3,080(w), 2,935(w), 2,860(w), 1,671(vs), 1,612(m), 1,566(w), 1,475(vs), 1,393(m), 1,347(s), $1,291(\mathrm{~s}), \quad 1,261(\mathrm{~m}), \quad 1,240(\mathrm{~m}), \quad 1,194(\mathrm{~m}), \quad 1,130(\mathrm{w}), \quad 1,104(\mathrm{~m}), \quad 1,067(\mathrm{~m})$, 1,011(w), 930(m), 853(m), 807(s), 726(m), 655(m), 599(m), 488(m), 431(m). Synthesis of ZIF-100. Under a dry nitrogen atmosphere a solid mixture of zinc(II) trifluoromethanesulphonate $\left(\mathrm{Zn}\left(\mathrm{O}_{3} \mathrm{SCF}_{3}\right)_{2}, 1.453 \mathrm{~g}, 4.0 \mathrm{mmol}\right)$ and cbIM $(6.103 \mathrm{~g}, 40.0 \mathrm{mmol})$ was dissolved in anhydrous DMF $(270 \mathrm{ml})$ in a $500 \mathrm{ml}$ container. Subsequently, $\mathrm{H}_{2} \mathrm{O}(5.8 \mathrm{ml})$ was added, the container capped and heated in an isothermal oven at $120^{\circ} \mathrm{C}$ for $48 \mathrm{~h}$ to give dark yellow cubic crystals. The reaction mixture was allowed to cool naturally to room temperature and the crystals were washed with DMF and dried in air. Yield: $1.012 \mathrm{~g}, 70.5 \%$ based on $\mathrm{Zn}\left(\mathrm{O}_{3} \mathrm{SCF}_{3}\right)_{2}$. Elemental microanalysis for $\mathrm{Zn}_{20}(\mathrm{cbIM})_{39}(\mathrm{OH}) \equiv$ $\mathrm{C}_{273} \mathrm{H}_{157} \mathrm{~N}_{78} \mathrm{O}_{1} \mathrm{Cl}_{39} \mathrm{Zn}_{20}$, calculated based on framework only (\%): C, 45.31; H, 2.19; N, 15.10; Cl, 19.11; Zn, 18.07. Found (\%): C, 45.11; H, 2.18; N, 14.79; $\mathrm{Cl}, 19.19 ; \mathrm{Zn}, 18.93$. FT-IR (KBr, 4,000-400 $\left.\mathrm{cm}^{-1}\right): 3,430(\mathrm{br}), 3,080(\mathrm{~m})$, $2,931(\mathrm{~m}), 2,860(\mathrm{w}), \quad 1,668(\mathrm{vs}), \quad 1,612(\mathrm{~s}), \quad 1,576(\mathrm{~m}), 1,573(\mathrm{w}), 1,475(\mathrm{vs})$, 1,437(m), 1,415(w), 1,342(s), 1,286(s), 1,256(m), 1,240(s), 1,195(s), 1,134(m), 1,098(m), 1,072(s), 1,014(w), 925(s), 859(m), 803(s), 762(w), 726(s), 659(m), 604(s), 487(m), 431(m).

Under these reaction conditions (metal, ligand, solvents, temperature, time, and so on), use of different counter anions (such as zinc(II) trifluoromethanesulphonate, nitrate, tetrafluoroborate, chloride) yield similar quantities of ZIF100. However, tuning the water content of the reaction ultimately controls the yield of ZIF-100. Therefore anions are not SDAs.

Activation of ZIF-95 and ZIF-100. As-synthesized samples of ZIF-95 were immersed in anhydrous acetone in a glove box for 3 days; during the exchange the acetone was refreshed three times. The resulting acetone-exchanged sample of ZIF-95 was transferred as a suspension to a quartz cell in a glove box and the solvent was decanted. The wet sample was then evacuated $\left(10^{-3}\right.$ torr $)$ at $50^{\circ} \mathrm{C}$ for $10 \mathrm{~h}$ then at $100^{\circ} \mathrm{C}$ for $12 \mathrm{~h}$. ZIF-100 was identically activated, except that anhydrous methanol was used as the exchange solvent.

Gas adsorption and separation measurements. Low-pressure gas adsorption experiments (up to 850 torr) were carried out on a Quantachrome AUTOSORB1 automatic volumetric instrument. Ultrahigh-purity-grade gases were used in all adsorption measurements. The $\mathrm{N}_{2}$ (for ZIF-95, $77 \mathrm{~K}$ ) and Ar (for ZIF-100, $87 \mathrm{~K}$ ) isotherms were measured using a liquid nitrogen and an argon bath, respectively. $\mathrm{CO}_{2}, \mathrm{CH}_{4}, \mathrm{CO}$ and $\mathrm{N}_{2}$ isotherms were also tested for both ZIF-95 and ZIF-100 at 273 and $298 \mathrm{~K}$, respectively.

ZIF-95. An apparent surface area of $1,240 \mathrm{~m}^{2} \mathrm{~g}^{-1}$ (Langmuir, the linearity of fitting, $R=0.9999$ ) was obtained by using the data points on the adsorption branch of the $\mathrm{N}_{2}$ isotherm in the range $P / P_{0}=0.1-0.35$ (Supplementary Information Section S5). A BET surface area of $1,050 \mathrm{~m}^{2} \mathrm{~g}^{-1}$ was obtained by using $P / P_{0}=0.03-0.08$. A micropore volume of $0.43 \mathrm{~cm}^{3} \mathrm{~g}^{-1}$ was obtained by applying non-local density functional theory (NLDFT) with a $\mathrm{N}_{2}$-zeolites and silica model on the adsorption branch (the fitting error was $0.155 \%$ ) (Supplementary Information Section S5).

ZIF-100. An apparent surface area of $780 \mathrm{~m}^{2} \mathrm{~g}^{-1}(R=0.9998)$ was obtained by using the data points on the adsorption branch of the Ar isotherm in the range $P / P_{0}=0.1-0.3$ (Supplementary Information Section S5). A BET surface area of $595 \mathrm{~m}^{2} \mathrm{~g}^{-1}$ was obtained by using $P / P_{0}=0.03-0.09$. A micropore volume of $0.37 \mathrm{~cm}^{3} \mathrm{~g}^{-1}$ was obtained by applying NLDFT with an Ar-zeolites and silica model on the adsorption branch (the fitting error was 0.095\%) (Supplementary Information Section S5).

The gas-separation properties of ZIF-95 and ZIF-100 were tested by breakthrough experiments using a $\mathrm{CO}_{2} / \mathrm{CH}_{4}, \mathrm{CO}_{2} / \mathrm{N}_{2}$ or $\mathrm{CO}_{2} / \mathrm{CO}$ (about 50:50 v/v) gas mixture. $1.2 \mathrm{~g}$ of activated ZIF- 95 and $1.1 \mathrm{~g}$ of activated ZIF- 100 were packed into a stainless-steel column $(0.46 \mathrm{~cm}$ inner diameter and $8 \mathrm{~cm}$ length $)$ in a glove box. The columns were then attached to gas-separation apparatus built as shown in Supplementary Fig. 32. Helium gas was used to initially purge the sample columns. All the experiments were carried out at room temperature. The gases ( 20 p.s.i.) were dosed into the column at a flow rate of $20 \mathrm{ml} \mathrm{min}^{-1}$. The relative amounts of the gases passing through the column were monitored on a Hiden Analytical HPR20 gas analysis system detecting ion peaks at $m / z^{+}=44\left(\mathrm{CO}_{2}\right), 16$ $\left(\mathrm{CH}_{4}\right), 28\left(\mathrm{~N}_{2}\right), 12(\mathrm{CO})$. 